\title{
Práticas desenvolvidas para a educação sustentável no ensino superior: contribuições do professor
}

\author{
Practices developed for sustainable education in higher education: teacher \\ contributions
}

\author{
Micaele Rodrigues Feitosa Melo ${ }^{a}$ \\ Ângela Maria de Souza ${ }^{b}$ \\ Agna Ligia Pinheiro Máximo ${ }^{c}$ \\ Antonio Thércio Silva Coutinho ${ }^{d}$ \\ a, b Faculdade de Juazeiro do Norte - FJN \\ a E-mail: micaele-melo@hotmail.com \\ bE-mail: angellaeu@gmail.com \\ c E-mail: agnaligia@hotmail.com \\ d E-mail: thercio01395@gmail.com
}

Recebido em: 20/01/2018 | Aceito em:27/06/2018

ARTIGO

\section{RESUMO}

A presente pesquisa visa identificar de que forma os professores contribuem para a educação sustentável no ensino superior analisando as práticas desenvolvidas por estes profissionais no ambiente de trabalho. É um trabalho baseado nas investigações de autores tais como Viegas e Cabral (2014) e Marcomin e Silva (2009) cujas pesquisas demonstraram o relevante papel das IES para o desenvolvimento sustentável. Para atender ao objetivo proposto desenvolveu-se um estudo descritivo e exploratório de abordagem quantitativa cuja realização se deu através da aplicação de questionário semiestruturado tendo como sujeitos da pesquisa os professores de uma Instituição de Ensino Superior da esfera privada da cidade de Juazeiro do Norte. Os resultados da pesquisa indicam que a maioria dos professores entrevistados são jovens, porém experientes. Grande parte gosta e conhece o tema sustentabilidade e saberiam dirimir dúvidas relacionadas sobre o tema. Contudo, observou-se que, apesar da experiência e do conhecimento acerca da sustentabilidade, as atitudes praticadas ainda precisam ser modificadas, pois para que seja possível desenvolver uma educação sustentável é necessário, 
preliminarmente, a colaboração de cada indivíduo, em especial dos professores que são as pessoas nas quais os alunos se inspiram. Com este estudo foi possível obter sugestões para o desenvolvimento de uma educação sustentável mais efetiva as quais servirão de subsídios não apenas para a IES onde este estudo foi realizado, mas para outras instituições que buscam o contínuo melhoramento da educação sustentável.

Palavras-chave: Educação Sustentável. Professores. Ensino Superior.

\section{ABSTRACT}

The present research aims to identify how teachers contribute to sustainable education in higher education by analyzing the practices developed by these professionals in the work environment. It is a work based on the investigations of authors such as Viegas and Cabral (2014) and Marcomin e Silva (2009) whose research demonstrated the relevant role of IES for sustainable development. In order to meet the proposed objective was developed a descriptive and exploratory study of a quantitative approach whose was carried out through the application of semistructured questionnaire having as subjects of the research the teachers of a Higher Education Institution of the private sphere of the city of Juazeiro do Norte. The research results indicate that the most of the teachers interviewed are young, but experienced. The great part likes and knows the theme sustainability and would be able to settle related doubts on the subject. However, it was observed that despite the experience and knowledge about sustainability, the practiced attitudes still need to be modified, because to be possible develop a sustainable education is necessary, preliminary, the collaboration of each individual, especially the teachers who are the people on whom the students are inspired. With this study was possible to obtain suggestions for the development of a more effective sustainable education that will serve as a subsidy not only for the IES where this study was carried out, but for other institutions that seek the continuous improvement of sustainable education.

Keywords: Sustainable Education. Teachers. Higher Education.

\section{INTRODUÇÃO}

Reconhecer que o meio ambiente pede socorro e que cada indivíduo possui uma parcela de culpa nos problemas ambientais é o primeiro passo para transformar as atitudes cotidianas em práticas sustentáveis. O problema é que a maioria dos indivíduos apresenta resistência a mudanças ainda que este processo apresente benefícios. Tal resistência existe porque estas mudanças implicam em transformações e medidas que nem sempre são fáceis de adotar (VIEGAS; CABRAL, 2014).

As Instituições de Ensino Superior (IES) vêm adotando práticas que sejam capazes de contribuir para a transformação do comportamento dos estudantes Ciência e Sustentabilidade - CeS / Juazeiro do Norte, v. 4, n. 1, p. 95-114, jan/jun - 2018 
Micaele Rodrigues Feitosa Melo;

Ângela Maria de Souza;

Agna Ligia Pinheiro Máximo;

Antonio Thércio Silva Coutinho

visando conscientizá-los acerca da importância da sustentabilidade. Tais ações fazem parte de um processo denominado educação sustentável ou educação para sustentabilidade definida pela Organização das Nações Unidas para a Educação, a Ciência e a Cultura (UNESCO) como uma dimensão particularmente importante da educação de qualidade (BARBIERI; SILVA, 2011).

A educação sustentável desperta na comunidade escolar e acadêmica o exercício de cidadania, o que para o Ministério da Educação (MEC) "[...] é um dos mais libertários momentos da vida de crianças, jovens e adultos". O manual de educação para o consumo sustentável elaborado pelo MEC descreve as mudanças comportamentais proporcionadas pela educação sustentável afirmando ser este o momento no qual os jovens adquirem a noção de direitos e deveres transcendendo os interesses individuais e traduzindo uma nova visão de mundo (BRASIL, 2005, p. $07)$.

Tendo em vista a forte influência que os professores exercem na vida de seus alunos através de projetos, cursos, ações e estratégias educativas que despertam no aluno o pensamento crítico e reflexivo acredita-se que o professor do ensino superior seja capaz de despertar nos alunos o interesse pela sustentabilidade modificando seus hábitos em ações sustentáveis e incentivando-os a colaborar com o desenvolvimento da educação sustentável, pois há várias relações no ambiente universitário, mas a relação professor-aluno é uma das mais importantes pois "é caracterizada pela troca de influências entre individualidades distintas, o que permite que se estabeleça um vínculo de dependência entres seus atores" (RONCAGLIO, 2004, p. 110).

Para Lima (2003) a educação para a sustentabilidade no Brasil ainda é pouco disseminada na literatura e nas práticas que relacionam educação e meio ambiente. Jacobi (2003) destaca que nessa época de globalização em que as informações são compartilhadas na velocidade do vento, a educação sustentável configura-se como uma prática motivadora com o intuito de sensibilizar e transformar o comportamento das pessoas na busca de uma vida melhor e mais saudável. Analisando as reflexões dos autores, é possível identificar que a educação sustentável possui grande relevância, justificando, desta forma, a importância desta pesquisa.

Ciência e Sustentabilidade - CeS / Juazeiro do Norte, v. 4, n. 1, p. 95-114, jan/jun - 2018 
Neste sentido, objetivou-se com este estudo identificar de que forma os professores contribuem para a educação sustentável no ensino superior analisando as práticas desenvolvidas por estes profissionais no ambiente de trabalho. De modo específico esta pesquisa visa verificar o comportamento dos professores frente a situações de (in)sustentabilidade, identificar as ações dos professores que contribuem para a educação sustentável no ambiente de trabalho e apresentar sugestões que possam contribuir com o desenvolvimento da educação sustentável no ensino superior.

Educar para a sustentabilidade significa, portanto, desenvolver a consciência crítica da sociedade e estimular práticas sustentáveis que transcendam os muros das escolas e/ou das IES, seja através de ensinamentos ou por meio do exemplo. Percebe-se deste modo, que o professor possui papel relevante nesta missão instigante e desafiadora que é o desenvolvimento da educação sustentável.

\section{DESAFIOS DA EDUCAÇÃO SUSTENTÁVEL NO ENSINO SUPERIOR}

A Educação Sustentável tem sido alvo de muitas discussões especialmente nas últimas décadas devido às crises ambientais e sociais pelas quais o planeta vem passando. A origem destas discussões está relacionada à criação da UNESCO, órgão das Nações Unidas considerado o grande precursor mundial dos debates educacionais gerais bem como das discussões acerca da Educação Sustentável. Este órgão surgiu principalmente no período pós-guerra em meados de 1940, com o intuito de "construir condições sociais e econômicas que garantissem a paz de forma duradoura" (BARBIERI; SILVA, 2011, p. 03).

No Brasil, a Educação para a Sustentabilidade começou a ter destaque em 1988, como um importante instrumento de políticas públicas, estabelecido pela constituição da República Federativa do Brasil, pela Política Nacional do Meio Ambiente (PNMA) e pela Política Nacional de Educação Ambiental (PNEA). A partir da Lei 6.938 da PNMA todas as modalidades de ensino formal e informal devem incluir a Educação para a Sustentabilidade em seus programas de forma permanente, inclusive aos programas de treinamentos e desenvolvimento de pessoas realizadas por organizações públicas e privadas (BARBIERI; SILVA, 2011). Ciência e Sustentabilidade - CeS / Juazeiro do Norte, v. 4, n. 1, p. 95-114, jan/jun - 2018 
Micaele Rodrigues Feitosa Melo;

Ângela Maria de Souza;

Agna Ligia Pinheiro Máximo;

Antonio Thércio Silva Coutinho

Para se referir à educação sustentável, Gadotti utiliza o termo "ecopedagogia" cujo objetivo está em promover uma educação balizada no desenvolvimento sustentável por meio da reflexão quanto às práticas sustentáveis que colaboram para um planeta melhor e mais saudável. Para o autor, esta discussão é indispensável devido à urgência do desequilíbrio ambiental decorrente, principalmente, das ações da sociedade. A educação sustentável envolve a "simplicidade voluntária" e "a quietude", pois a vida dos indivíduos deve estar centrada em novos valores, a saber: "simplicidade, austeridade, quietude, paz, serenidade, saber escutar, saber viver juntos, compartir, descobrir e fazer juntos" (GADOTTI, 2013, p. 16).

O uso incorreto da água e iluminação é algo comum no ambiente educacional assim como é elevada a quantidade de alimentos desperdiçados nestes espaços. A utilização desnecessária de papéis, a torneira aberta, lâmpadas e ventiladores ligados são ações rotineiras que causa graves prejuízos ao meio ambiente. Migueis salienta que não adianta falar em redução do consumo se as instituições não aproveitarem os recursos naturais e se não desenvolverem ações que promovam o uso consciente e racional. Diante do atual cenário ambiental, onde o consumismo tem se alastrado por todas as esferas, torna-se difícil apontar alternativas para o desenvolvimento da educação sustentável (MIGUEIS, 2014).

Nas Instituições de Ensino Superior a situação não é diferente pois, apesar de ser um local frequentando por adultos, ainda há muitas atitudes que precisam ser modificadas tanto em relação ao comportamento dos alunos como referente às práticas dos professores. Por isto, as diversas instâncias e órgãos institucionais, entre decisores e funcionários, docentes e discentes, devem agir em conjunto com plena cooperação entre as partes a fim de promover a sensibilização e conscientização da comunidade acadêmica sobre a importância da sustentabilidade ambiental no ensino superior (MARCOMIN; SILVA, 2009).

Desenvolver uma educação sustentável, portanto, vai além de estudos voltados ao meio ambiente, pois envolve mudanças de práticas e comportamentos. Além disto, o meio ambiente é um sistema que sofre influências de todas as esferas, exigindo assim, o envolvimento de todos os indivíduos na busca de uma sociedade 
mais sustentável. A chamada "crise ambiental" alerta para a necessidade de conscientização e reflexão acerca das contribuições das organizações para a sustentabilidade. Assim, o ser humano precisa, não apenas saber em qual lixeira ele deve jogar papel, mas também ter a consciência dos prejuízos que uma atitude irresponsável traz ao meio ambiente e consequentemente a ele próprio (VIEGAS; CABRAL, 2014).

Verifica-se deste modo, que educar para a sustentabilidade no ensino superior não é fácil especialmente por causa do comportamento engessado dos alunos. Por isto, as Instituições de Ensino Superior (IES) devem realizar a sensibilização e conscientização de toda a comunidade acadêmica acerca da importância do desenvolvimento sustentável através da cooperação mútua entre dirigentes, discentes, docentes e colaboradores. Além disto, o estudo da sustentabilidade não deve ser prática exclusiva de docentes e pesquisadores, primeiro porque as IES não existem de forma isolada, e segundo por causa do contexto social no qual estão inseridas (MARCOMIN; SILVA, 2009).

Analisando as palavras de Marcomin e Silva (2009) verifica-se que toda a comunidade acadêmica é responsável pela educação sustentável no ensino superior, mas os professores merecem destaque quanto à capacidade de influenciar pessoas a mudarem seus hábitos e comportamentos. Isto porque na maioria das vezes o aluno acompanha os passos do professor sem nenhuma ponderação acerca da sua postura profissional, o que aumenta a responsabilidade e implica uma prática conexa aos seu discurso (RONCAGLIO, 2004).

Ao comentar sobre as práticas sustentáveis no ensino superior que podem transformar a vida dos estudantes, Becker et al. (2015) mencionam a pedagogia da paixão de Shrivastava (2010) cuja técnica pode ser trabalhada por meio de um ensino globalizante que ajude os alunos a resolverem problemas unindo a aprendizagem emocional, física e espiritual com a aprendizagem tradicional através do conhecimento dos alunos sobre as práticas sustentáveis. Devido à amplitude dos espaços acadêmicos, o papel do professor como incentivador de práticas sustentáveis é fundamental já que este profissional está mais próximo do aluno.

Ciência e Sustentabilidade - CeS / Juazeiro do Norte, v. 4, n. 1, p. 95-114, jan/jun - 2018 
Micaele Rodrigues Feitosa Melo;

Ângela Maria de Souza;

Agna Ligia Pinheiro Máximo;

Antonio Thércio Silva Coutinho

Além disto, o meio acadêmico é um espaço perfeito para despertar nos sujeitos a importância desta temática, pois conforme afirma Migueis (2014) este assunto precisa ser debatido a fim de que haja "mudanças de valores e de atitudes para a construção de sociedades sustentáveis". A autora complementa dizendo: "Em um planeta que a cada dia se torna mais descartável, surge à escola (ou às IES) a necessidade de mudar esse cenário, através do cuidado, do diálogo e da integridade, [...] pois, a responsabilidade é individual, mas a preservação do planeta precisa ser coletiva" (MIGUEIS, 2014, p. 01).

Há várias formas de desenvolver ações para a sensibilização do desenvolvimento sustentável no ensino superior a começar pelo planejamento e gestão as atividades e ensino, pesquisa e extensão. A aquisição de materiais recicláveis, o uso de uma logística que evite a agressão ao meio ambiente, operações que demonstrem a preocupação da IES com o futuro do planeta também podem servir de exemplo para a comunidade acadêmica no que tange às práticas para uma educação sustentável (DRAHEI, et al., 2017).

É inegável a importância dos conteúdos pertinentes a questão ambiental nos currículos escolares e acadêmicos. Contudo, para uma prática sustentável verdadeiramente efetiva no ambiente acadêmico, a reflexão e ação dos professores nos corredores das IES talvez seja o principal fator para uma educação sustentável tendo em vista as relevantes contribuições que estes profissionais oferecem à vida acadêmica e profissional de um aluno (BRANDÃO, et al., 2017)

Verifica-se, portanto, que a atuação do docente deve exercer um papel incentivador para o desenvolvimento de atividades que possam despertar o interesse dos acadêmicos para o desenvolvimento de práticas sustentáveis. Para tanto, se faz necessário que o professor seja o agente principal deste processo sendo o principal influenciador e dando exemplos diários de práticas sustentáveis para que assim, os alunos tornem-se conscientes das suas responsabilidades com meio ambiente.

\section{PROCEDIMENTOS METODOLÓGICOS}

Ciência e Sustentabilidade - CeS / Juazeiro do Norte, v. 4, n. 1, p. 95-114, jan/jun - 2018 
O presente estudo constitui uma pesquisa de natureza descritiva e exploratória com abordagem quantitativa realizada com os professores de uma Instituição de Ensino Superior (IES) classificada como Instituição com fins lucrativos localizada na cidade de Juazeiro do Norte. O estudo de caso foi a técnica utilizada para o desenvolvimento deste estudo, pois conforme afirma Bertucci (2011) esta técnica busca responder como e porque determinada situação ocorre, além de ser a técnica mais utilizada nas ciências sociais.

Utilizou-se como critério de inclusão ser professor do ensino superior legalmente ativo. Foram excluídos do estudo os professores que atuam em campos de estágio (preceptores), professores que apresentaram atestado médico cuja vigência contemplava o período de coleta de dados, professores que fazem parte do núcleo gestor da IES (diretores geral e acadêmico) e professores que deixaram de responder mais de $50 \%$ das questões relativas a este estudo. O corpo docente da IES possui 149 professores dos quais 112 se enquadraram nos critérios de inclusão e 49 devolveram os questionários devidamente respondidos, sendo esta a quantidade de respondentes.

A realização da pesquisa aconteceu durante os meses de agosto e setembro de 2017 sendo que o convite foi feito em ambiente reservado e de forma individualizada a fim de que os participantes ficassem mais à vontade para aceitar ou recusar a participação na pesquisa. Em seguida foi realizada a coleta de dados por meio de um questionário semiestruturado composto por seis questões relacionadas ao perfil dos entrevistados e sete questões referentes ao tema desta pesquisa com o objetivo de identificar de que forma os professores do ensino superior contribuem para o desenvolvimento de uma educação sustentável a fim de sensibilizá-los sobre a importância da sua atuação na construção deste processo.

\section{RESULTADOS E DISCUSSÃO}

Esta pesquisa foi desenvolvida em uma IES que atua no mercado há 14 anos e possui atualmente 149 docentes. Preliminarmente, a pesquisa buscou traçar o perfil dos entrevistados visando identificar a faixa etária, sexo e tempo de 
Micaele Rodrigues Feitosa Melo;

Ângela Maria de Souza;

Agna Ligia Pinheiro Máximo;

Antonio Thércio Silva Coutinho

experiência, tanto profissional quanto na IES em questão, bem como em quais cursos os respondentes ministram aulas.

Participaram da pesquisa 24 homens e 25 mulheres dos quais 29 possuem idade inferior a 40 anos. Dos 49 participantes, 33 possuem mais de 06 anos de experiência profissional sendo que 39 professores atuam na IES estudada há mais de três anos. Este resultado demonstra que os participantes da pesquisa são jovens, porém experientes o que leva a compreensão de que possuem o conhecimento necessário para responder as questões da pesquisa, tendo em vista todos possuírem trajetória profissional consolidada. Para Freire (2007) os professores, em especial os jovens, precisam analisar a sua prática e postura profissional devido às diferentes formas de pensar e agir pois só assim a educação para a sustentabilidade se tornará uma realidade nos ambientes educacionais.

A pesquisa conseguiu alcançar professores que ministram aula em todos os 07 cursos existentes na IES, quais sejam, enfermagem (09), farmácia (10), nutrição (12), ciências contábeis (06), sistemas de informação (08), arquitetura e urbanismo (02) e segurança do trabalho (02). Este resultado foi importante para a pesquisa pois foi possível estudar a sustentabilidade sob a perspectiva de áreas variadas, permitindo assim, a ampliação das contribuições deste estudo através da interdisciplinaridade. Para Alves, a educação sustentável deve acontecer em espaços distintos de aprendizagem com abordagem interdisciplinar pois as consequências oriundas das práticas in(sustentáveis) afetam a sociedade em diferentes aspectos (ALVES, 2014).

A segunda parte da pesquisa analisou a relação existente entre o tema sustentabilidade e as disciplinas ministradas pelos entrevistados bem como o conhecimento dos entrevistados acerca deste assunto. Sobre a relação entre as disciplinas ministradas pelos professores e o tema da sustentabilidade apenas 07 professores disseram que suas disciplinas não têm nada a ver com sustentabilidade.

Este resultado mostra que, embora o tema sustentabilidade não esteja inserido nos conteúdos programáticos de todas as disciplinas, esta temática está ligada, mesmo que indiretamente, a diversos campos do saber. Miranda e Pereira (2017) falam sobre a importância da reestruturação dos currículos educacionais no

Ciência e Sustentabilidade - CeS / Juazeiro do Norte, v. 4, n. 1, p. 95-114, jan/jun - 2018 
que tange ao direcionamento de práticas sustentáveis, pois a sustentabilidade é um tema que permeia diversas áreas. Para os autores, o estudo da sustentabilidade é essencial para a formação cidadã sendo indispensável para a construção de um futuro melhor, justificando assim, a importância do professor universitário possuir conhecimento, ainda que superficial, sobre sustentabilidade.

Quanto a compreensão do conceito sustentabilidade foi perguntado aos professores se eles saberiam explicar aos alunos o conceito de sustentabilidade. Dos 49 docentes entrevistados, 23 afirmaram ser muito ligados a este tema e por isto, com certeza conseguiriam explicar com clareza tal conceito. Em contrapartida, 27 professores afirmaram que talvez fosse possível falar sobre o assunto, mas com base no conhecimento popular ou através de pesquisa prévia. A figura 1 mostra todos os resultados obtidos através desta questão.

Figura 1. Compreensão do conceito de sustentabilidade

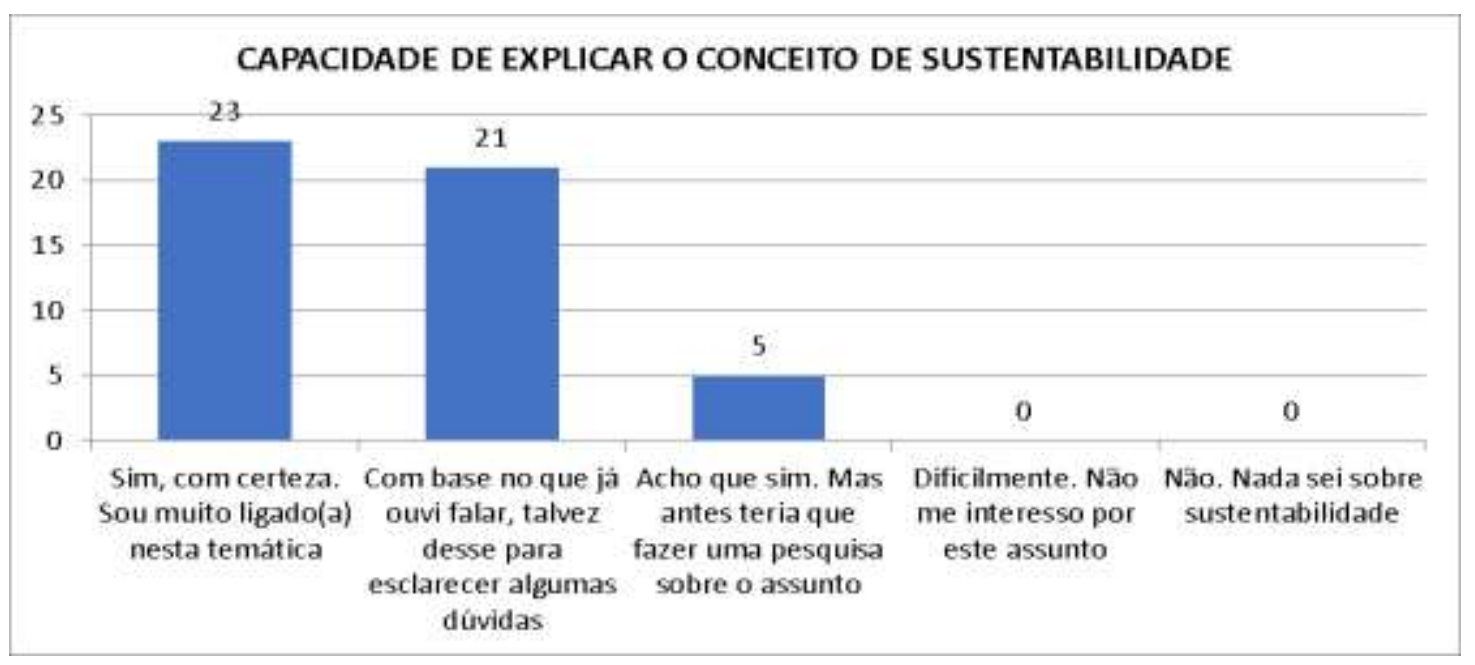

Fonte: Elaboração própria com dados da pesquisa.

Com este resultado é possível afirmar que os docentes estão cada vez mais interessados neste tema e que o conhecimento dos docentes acerca da sustentabilidade é positivo já que nenhum dos entrevistados relatou não se interessar ou não saber nada sobre sustentabilidade. Contudo, 0 fato de 27 professores não conseguirem falar sobre a sustentabilidade de forma segura, alerta para a necessidade de ações específicas para melhor compreensão deste assunto. Projetos, cursos e pesquisas voltados ao tema da sustentabilidade têm crescido nas últimas décadas. Verifica-se assim, que a busca de soluções para a redução dos 
Micaele Rodrigues Feitosa Melo;

Ângela Maria de Souza;

Agna Ligia Pinheiro Máximo;

Antonio Thércio Silva Coutinho

impactos causados pela (in)sustentabilidade ainda é um desafio para a sociedade contemporânea haja vista ser necessária sólida argumentação e conhecimento por parte dos profissionais, em especial dos professores (TEIXEIRA; TOLARES, 2014).

A pesquisa buscou ainda verificar o comportamento dos entrevistados diante de situações consideradas (in)sustentáveis. Para este fim, foi citado como exemplo "ver um colega/aluno jogando lixo no chão ou deixando a torneira do banheiro aberta". As respostas apontaram que apenas 03 professores chamariam a atenção da pessoa irritadamente mesmo que fosse um colega ou um aluno, enquanto que 14 professores desfariam a ação para não criar problemas com os colegas/alunos. A maioria, 32 professores, disseram que fariam a correção, mas de forma gentil a fim de conscientizar a pessoa das consequências daquela atitude irresponsável. A figura 02 mostra os resultados obtidos através desta pergunta.

Figura 2. Comportamento dos professores diante de situações de (in)sustentabilidade

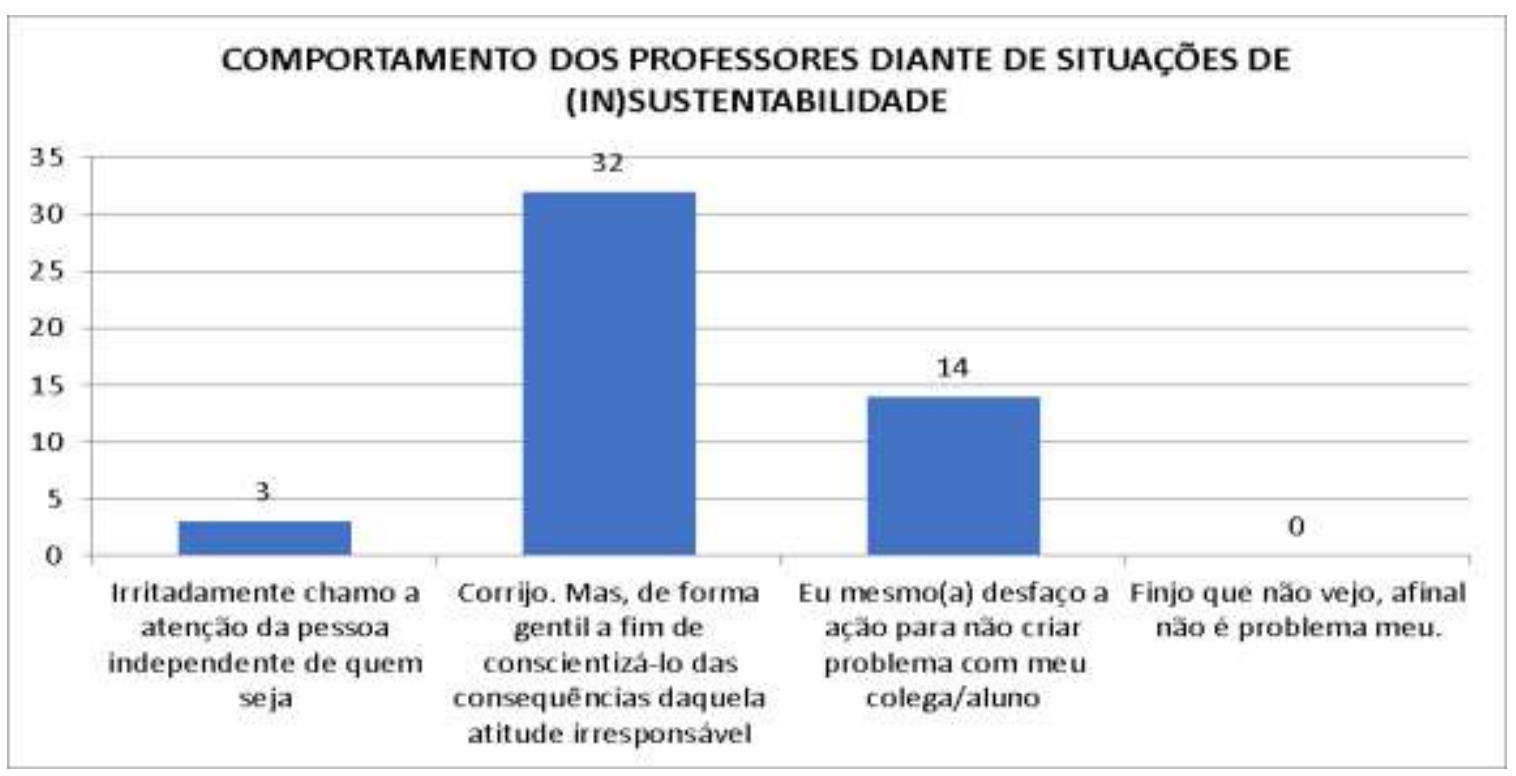

Fonte: Elaboração própria com dados da pesquisa.

A partir da figura 2 é possível observar que alguns professores ainda não entenderam seu real papel no ambiente acadêmico, pois a postura de um professor diante de atitudes erradas é de corrigir e não apenas desfazer o erro. Chamar atenção de um colega/aluno por estar jogando no lixo é uma forma de educá-lo e conscientizá-lo a não errar novamente. É preciso ser educador além dos muros da sala de aula, pois conforme afirma Migueis no aporte teórico deste estudo, o diálogo

Ciência e Sustentabilidade - CeS / Juazeiro do Norte, v. 4, n. 1, p. 95-114, jan/jun - 2018 
e a integração no ambiente educacional são indispensáveis para a melhoria das práticas sustentáveis, haja vista a preservação do planeta ser dever e responsabilidade de todos (MIGUEIS, 2014).

A quarta pergunta do questionário solicitou que os professores marcassem a(s) ação(ões) praticadas usualmente no ambiente de trabalho que contribuem com a educação sustentável. As respostas obtidas estão apresentadas no quadro 1:

Quadro 1. Ações que contribuem para a educação sustentável no ensino superior

\begin{tabular}{|l|c|}
\hline $\begin{array}{c}\text { Marque o(s) item(s) que descreve(m) como você contribui para a } \\
\text { educação sustentável no ensino superior }\end{array}$ & QTDE \\
\hline $\begin{array}{l}\text { Tenho meu próprio copo/garrafa para beber água. Não utilizo copos } \\
\text { descartáveis. }\end{array}$ & 18 \\
\hline Ao finalizar a aula desligo as lâmpadas e o data show. & 44 \\
\hline $\begin{array}{l}\text { Sempre que possível, solicito aos funcionários responsáveis que } \\
\text { desliguem a central de ar quando a aula termina. }\end{array}$ & 24 \\
\hline Desligo o computador institucional quando não vou mais utilizá-lo. & 37 \\
\hline $\begin{array}{l}\text { Evito utilizar material impresso. Prefiro projetar em slides para } \\
\text { economizar papel. }\end{array}$ & 35 \\
\hline Quando preciso fazer impressão sempre faço frente e verso. & 35 \\
\hline Utilizo as sobras de material impresso para fazer rascunho. & 33 \\
\hline Descarto o lixo nos coletores corretamente. & 44 \\
\hline $\begin{array}{l}\text { Converso com os alunos sobre a importância das práticas } \\
\text { sustentáveis. }\end{array}$ & 26 \\
\hline Incentivo meus alunos a comprarem produtos ecológicos. & 5 \\
\hline Sempre que posso, participo de eventos ligados à sustentabilidade. & 20 \\
\hline
\end{tabular}

Fonte: Elaboração própria com dados da pesquisa.

As respostas obtidas permitem verificar que poucos professores incentivam os alunos a adquirirem produtos ecológicos, o que leva a compreensão de que os professores não estão exercendo o seu papel de conscientização no ambiente educacional. Verifica-se neste ponto a importância do desenvolvimento da pedagogia da paixão, mencionada no desenvolvimento teórico desta pesquisa, cuja finalidade principal é cultivar um processo ensino-aprendizagem holístico de modo a envolver aspectos, não somente teóricos, mas também humanísticos (SHRIVASTAVA, 2010, apud BECKER, et al. 2015). 
Micaele Rodrigues Feitosa Melo;

Ângela Maria de Souza;

Agna Ligia Pinheiro Máximo;

Antonio Thércio Silva Coutinho

Verificou-se ainda que dos 49 professores, 31 não possuem sua própria garrafa/copo demonstrando que a maioria destes profissionais está dando mal exemplo aos alunos. Levando-se em consideração a quantidade de professores ativos na IES analisada (149) e considerando que cada professor utilize um copo descartável a cada hora/aula, estima-se uma média de 3.752 copos descartáveis por semana, um número muito alto tendo em vista a média de tempo que o plástico leva para se decompor, o qual, segundo o Ministério do Meio Ambiente é de mais de 400 anos (BRASIL, 2005).

Os professores foram indagados ainda sobre quais ações consideravam mais difíceis de colocar em prática, sendo solicitada também a justificativa de cada escolha. De acordo com as respostas obtidas foi possível verificar que os professores não sentem dificuldade em desligar o computador institucional após o uso e em fazer impressão frente e verso já que nenhum dos respondentes mencionaram tais ações. Todas as demais ações foram mencionadas sendo as justificativas, ora iguais, ora diferentes, conforme observado no quadro 2 .

Quadro 2. Ações sustentáveis consideradas difíceis de praticar seguidas das justificativas

\begin{tabular}{|c|c|c|}
\hline $\begin{array}{l}\text { Das atitudes descritas na questão } \\
\text { anterior qual você considera mais } \\
\text { difícil de colocar em prática }\end{array}$ & Justificativa & $\begin{array}{c}\text { № de } \\
\text { Respostas }\end{array}$ \\
\hline \multirow{2}{*}{$\begin{array}{c}\text { Tenho meu próprio copo/garrafa para } \\
\text { beber água. Não utilizo copos } \\
\text { descartáveis }\end{array}$} & Questões de higiene & 01 \\
\hline & Dificuldade em adotar garrafa & 04 \\
\hline $\begin{array}{l}\text { Ao finalizar a aula desligo as } \\
\text { lâmpadas e o data show }\end{array}$ & Sou esquecido(a) & 01 \\
\hline $\begin{array}{l}\text { Sempre que possível, solicito aos } \\
\text { funcionários responsáveis que } \\
\text { desliguem a central de ar quando a } \\
\text { aula termina }\end{array}$ & $\begin{array}{l}\text { Os responsáveis dificilmente } \\
\text { estão por perto }\end{array}$ & 01 \\
\hline \multirow{2}{*}{$\begin{array}{l}\text { Evito utilizar material impresso. Prefiro } \\
\text { projetar em slides para economizar } \\
\text { papel. }\end{array}$} & $\begin{array}{c}\text { Discussões grupais exigem o } \\
\text { uso do material impresso }\end{array}$ & 04 \\
\hline & $\begin{array}{c}\text { Necessidade de utilizar papel } \\
\text { quase todo o tempo }\end{array}$ & 01 \\
\hline $\begin{array}{c}\text { Utilizo as sobras de material impresso } \\
\text { para fazer rascunho }\end{array}$ & Sou esquecido(a) & 01 \\
\hline $\begin{array}{l}\text { Descarto o lixo nos coletores } \\
\text { corretamente }\end{array}$ & $\begin{array}{c}\text { Nem sempre há coletores } \\
\text { disponíveis }\end{array}$ & 11 \\
\hline \multirow[b]{2}{*}{$\begin{array}{l}\text { Converso com os alunos sobre a } \\
\text { importância das práticas sustentáveis }\end{array}$} & $\begin{array}{c}\text { A temática não tem relação } \\
\text { com a disciplina }\end{array}$ & 01 \\
\hline & $\begin{array}{l}\text { Nem sempre os alunos se } \\
\text { importam }\end{array}$ & 03 \\
\hline
\end{tabular}

Ciência e Sustentabilidade - CeS / Juazeiro do Norte, v. 4, n. 1, p. 95-114, jan/jun- 2018 


\begin{tabular}{|c|c|c|}
\multirow{4}{*}{$\begin{array}{c}\text { Incentivo meus alunos a comprarem } \\
\text { produtos ecológicos }\end{array}$} & $\begin{array}{c}\text { Falta de incentivo desde a pré- } \\
\text { escola }\end{array}$ & 01 \\
\cline { 2 - 3 } & Produtos são caros & 02 \\
\hline \multirow{2}{*}{$\begin{array}{c}\text { Sempre que posso, participo de } \\
\text { eventos ligados à sustentabilidade }\end{array}$} & $\begin{array}{c}\text { Baixa oferta de cursos/ falta de } \\
\text { divulgação }\end{array}$ & 06 \\
\cline { 2 - 3 } & Falta de tempo & 06 \\
\hline \multicolumn{2}{|c|}{ Não responderam } & 06 \\
\hline
\end{tabular}

Fonte: Elaboração própria com dados da pesquisa.

Os resultados do quadro 2 demonstram que a maior dificuldade dos professores está relacionada ao correto descarte de lixo nos coletores por que nem sempre há coletores disponíveis. Infelizmente este é um problema que afeta não apenas a IES analisada, pois de acordo com pesquisa realizada por Conke e Nascimento (2018) a coleta seletiva, apesar de ser um tema muito disseminada pela sociedade, ainda é bastante incipiente pois esta prática é exercida em apenas $41 \%$ dos municípios brasileiros e apenas $10 \%$ dos materiais potencialmente recicláveis, são de fato recolhidos.

As respostas também demonstraram que os professores dificilmente participam de eventos ligados à sustentabilidade tanto por falta de tempo como por causa da baixa oferta/divulgação de cursos voltados a este tema. Este resultado vai ao encontro do pensamento de Marcomin e Silva (2009) ao destacarem o importante papel das IES para a educação sustentável. Para os autores, a consciência ambiental dos profissionais que serão formados pelas IES, depende necessariamente da responsabilidade socioambiental de cada instituição, especialmente no que diz respeito às atividades de extensão universitária.

Assim, é possível afirmar que as IES devem trabalhar de forma mais efetiva no desenvolvimento de eventos que destaquem a relevância da sustentabilidade pois, deste modo, além de cumprir o seu papel de educar para a sustentabilidade, também estará oportunizando aos docentes, maior aproximação com o universo sustentável e como resultado terá profissionais mais engajados e conscientes da importância deste tema.

Os professores foram indagados também sobre a importância de haver cursos de extensão, palestras e eventos relacionados à sustentabilidade nas IES. O 
Micaele Rodrigues Feitosa Melo;

Ângela Maria de Souza;

Agna Ligia Pinheiro Máximo;

Antonio Thércio Silva Coutinho

resultado obtido foi positivo haja vista todos os entrevistados terem reconhecido a importância de tais ações no ensino superior, conforme mostra a figura 3.

Figura 3. Consideração dos professores sobre a realização de cursos, palestras e oficinas sobre sustentabilidade

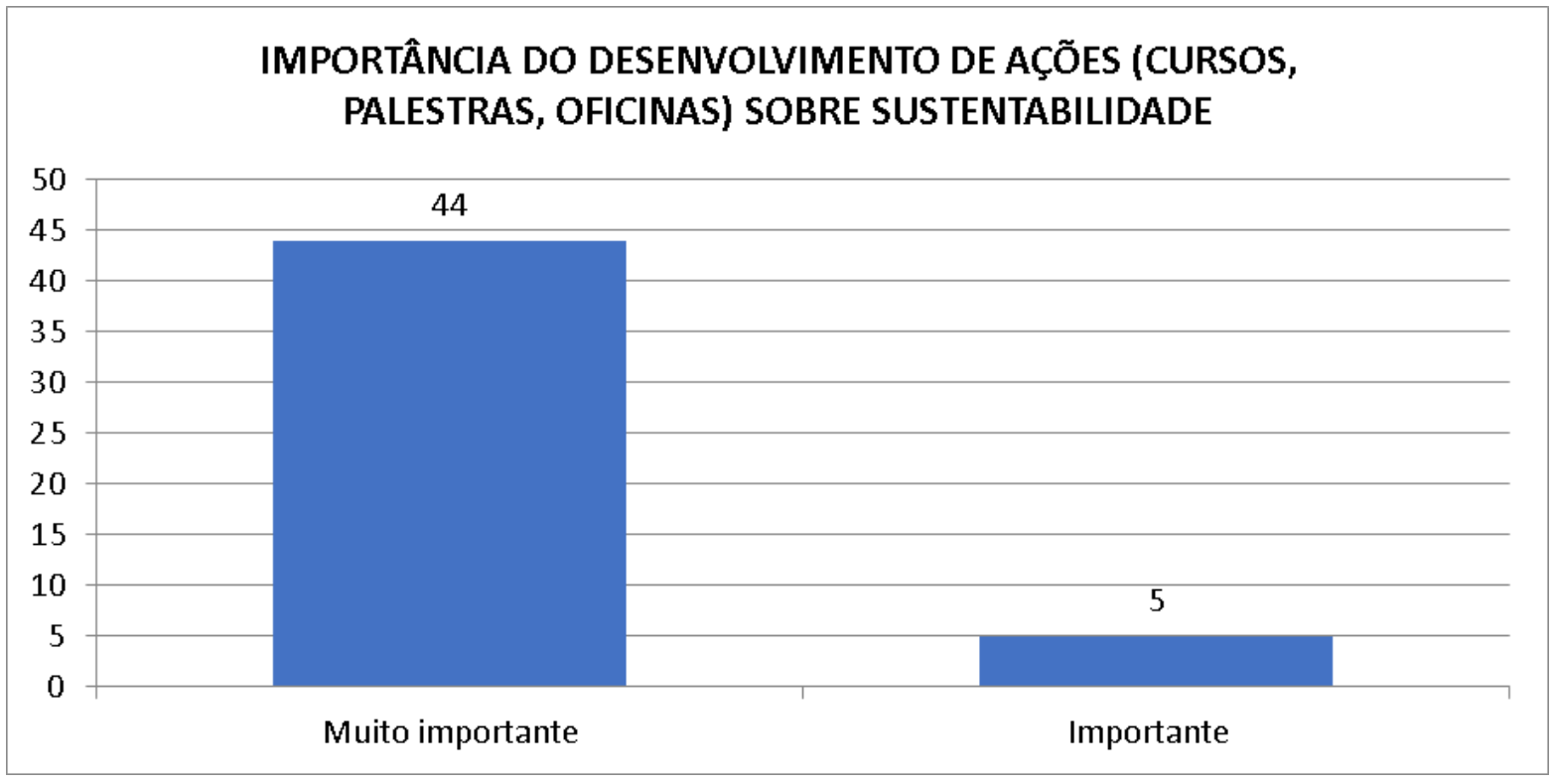

Fonte: Elaboração própria com dados da pesquisa.

Este resultado demonstra o quão é importante discutir sobre sustentabilidade no ensino superior e reforça as palavras de Barbieri e Silva (2011) mencionadas na introdução deste estudo. Para os autores as ações desenvolvidas pelas IES, tais como cursos, projetos e eventos acerca da sustentabilidade, transformam o comportamento da comunidade acadêmica e fazem parte das dimensões para uma educação de qualidade. O respaldo deste resultado é verificado também nas palavras de Marcomin e Silva (2009) ao falarem sobre a extensão da responsabilidade das IES que, segundo os autores, deixa de ser apenas social para se tornar uma responsabilidade ambiental, necessitando de melhoria nas conjunturas materiais e culturais.

Por fim, a pesquisa averiguou se os professores teriam alguma sugestão para o desenvolvimento da educação sustentável no ensino superior. Dos 49 respondentes, 12 não apresentaram sugestões enquanto os demais sugeriram que a IES deveria criar um código de postura e implantar um programa institucional permanente de ações voltadas à conscientização da importância da sustentabilidade

Ciência e Sustentabilidade - CeS / Juazeiro do Norte, v. 4, n. 1, p. 95-114, jan/jun - 2018 
no ensino superior através de reuniões e eventos. Também foi sugerido o uso de papel reciclável, a utilização de energias renováveis e a realização de oficinas não apenas para o público acadêmico, mas para toda a sociedade.

Professores da área da saúde sugeriram a reutilização da água dos equipamentos analíticos, a criação de hortas comunitárias e o uso de sobras de cascas de alimentos como adubos e sementes. Por fim, os professores mencionaram a inserção do tema sustentabilidade nas ementas das disciplinas e a inclusão de uma disciplina específica de sustentabilidade como optativa em todos os cursos.

Verifica-se nas sugestões destacadas pelos professores, a necessidade de ações mais efetivas no que tange à educação sustentável nas IES. Tais ações implicam novos modelos de gestão que sejam capazes de incorporar ao tripé da educação de nível superior - ensino, pesquisa e extensão - um movimento de transformação e mudanças de comportamento por meio de medidas que possibilitem resultados cada vez mais satisfatórios (VIEGAS; CABRAL, 2014).

Neste contexto, percebe-se que, embora os professores participantes desta pesquisa sejam familiarizados com o tema da sustentabilidade, ainda adotam uma postura inadequada quanto à educação sustentável no ensino superior, conforme mostra os resultados desta pesquisa.

Observa-se uma atenção dos professores em relação à necessidade da inserção da sustentabilidade no ensino superior, mas faz-se necessário que as IES adotem uma gestão estratégica e eficiente no sentido de ampliar e intensificar a conscientização dos professores e alunos quanto aos ganhos gerados a partir da educação sustentável.

\section{CONSIDERAÇÕES FINAIS}

Esta pesquisa buscou identificar de que forma os professores contribuem para a educação sustentável no ensino superior analisando as práticas desenvolvidas por estes profissionais no ambiente de trabalho. Analisaram-se aspectos ligados ao conhecimento do professor sobre sustentabilidade, Ciência e Sustentabilidade - CeS / Juazeiro do Norte, v. 4, n. 1, p. 95-114, jan/jun - 2018 
Micaele Rodrigues Feitosa Melo;

Ângela Maria de Souza;

Agna Ligia Pinheiro Máximo;

Antonio Thércio Silva Coutinho

comportamento diante de situações (in)sustentáveis bem como atitudes praticadas que impactam positiva ou negativamente para a educação sustentável.

Verificou-se que a maioria dos professores entrevistados são jovens, porém experientes. Grande parte gosta e conhece o tema da sustentabilidade e saberiam dirimir dúvidas relacionadas ao tema. Contudo, observou-se que, apesar da experiência e do conhecimento acerca da sustentabilidade, as atitudes dos professores ainda precisam ser modificadas, pois para que seja possível desenvolver uma educação sustentável é necessário, preliminarmente, a colaboração de cada indivíduo, em especial dos professores que são as pessoas nas quais os alunos se inspiram.

Com este estudo foi possível obter sugestões para o desenvolvimento de uma educação sustentável mais efetiva as quais servirão de subsídios não apenas para a IES onde este estudo foi realizado, mas para outras instituições que buscam o contínuo melhoramento da educação sustentável. Desta forma, é possível afirmar que o objetivo deste estudo foi atingido, tendo em vista os resultados obtidos e a forte contribuição que trará para o desenvolvimento de novas pesquisas.

Recomenda-se, portanto, que as instituições de ensino desenvolvam ações que possam contribuir com o desenvolvimento sustentável colocando em prática as sugestões expostas neste trabalho, pois assim, os professores começarão a (re) pensar suas atitudes, as quais se estenderão aos estudantes e comunidade, fazendo com que a educação sustentável seja praticada e disseminada nos mais diversos âmbitos educacionais.

\section{REFERÊNCIAS}

ALVEZ, Nilo Barcelos. Educação para a Sustentabilidade: uma abordagem interdisciplinar. In: XVI ENGEMA - Encontro Internacional sobre gestão empresarial e meio ambiente. ISSN 2359-1048. Disponível em: http://www.engema.org.br/XVIENGEMA/282.pdf. Acesso em 18 Jun. 2018.

BARBIERI, José Carlos; SILVA, Dirceu da. Desenvolvimento sustentável e educação ambiental: uma trajetória comum com muitos desafios REV. ADM. MACKENZIE, V. 12, N. 3, Edição Especial. SÃO PAULO, SP. 2011. ISSN 16786971. Disponível em: < http://www.scielo.br/pdf/ram/v12n3/a04v12n3.pdf:. Acesso em 04 Ago. 2017.

Ciência e Sustentabilidade - CeS / Juazeiro do Norte, v. 4, n. 1, p. 95-114, jan/jun - 2018 
BECKER, Deisi Viviane. ÁVILA, Lucas Veiga. NASCIMENTO, Luis Felipe Machado do. MADRUGA, Lúcia Rejane da Rosa Gama. Educação para a sustentabilidade no Ensino Superior: O papel do docente na formação do Administrador. Revista Eletrônica em Gestão, Educação e Tecnologia Ambiental Santa Maria, v. 19, n. 3, set-dez. 2015, p. 615-628 Revista do Centro de Ciências Naturais e Exatas - UFSM ISSN : 22361170. Disponível em:

https://periodicos.ufsm.br/reget/article/viewFile/16413/pdf. Acesso em 18 Jun. 2018.

BERTUCCI, Janete Lara de Oliveira. Metodologia Básica para elaboração de Trabalhos de Conclusão de Cursos (TCC): ênfase na elaboração de TCC de Pósgraduação Latu Sensu. 1. ed. 3. reimp. São Paulo: Atlas, 2011.

BRANDÃO, Janaína Balk. SILVA, Douglas Rodrigues Da. MACHADO, Gabriella Eldereti .SILVA, Jossiane Ortiz. Extensão Universitária: Formação De Professores À Distância Para Educação Ambiental. In: 6 Fórum Internacional Ecoinovar Santa Maria/RS - 21 a 23 de Agosto de 2017. Disponível em:

$<$ http://ecoinovar.com.br/cd2017/arquivos/artigos/ECO1622.pdf>. Acesso em 18 Jun. 2018.

BRASIL. Ministério do Meio Ambiente - MMA. Coleta Seletiva. Disponível em: http://www.mma.gov.br/cidades-sustentaveis/residuos-solidos/catadores-demateriais-reciclaveis/reciclagem-e-reaproveitamento. Acesso em 07 Out. 2017.

. MMA/ MEC/ IDEC. Manual de Educação para o Consumo Sustentável. Brasília: Consumers International, 2005. 160 p. ISBN 85-87166-73-5. Disponível em http://portal.mec.gov.br/dmdocuments/publicaca08.pdf. Acesso em 18 Ago. 2017.

CONKE, Leonardo Silveira. NASCIMENTO, Elimar Pinheiro do. A coleta seletiva nas pesquisas brasileiras: uma avaliação metodológica. urbe. Revista Brasileira de Gestão Urbana (Brazilian Journal of Urban Management), 2018 jan./abr., 10(1), 199212. Disponível em http://www.scielo.br/pdf/urbe/v10n1/2175-3369-urbe-10-1199.pdf>. Acesso em 18 Jun. 2018.

CUNHA, Gilma lale C. da. CUNHA, Jhose lale C. da. GADOTTI, Moacir. Educar para Sustentabilidade: Uma contribuição à Década da Educação para o Desenvolvimento Sustentável. São Paulo: Ed, L, 2008. 127 p. (Série Unifreire, 2) http://periodicos.uern.br/index.php/contexto/article/viewFile/1043/571

DRAHEI, Alfred Douglas. DAGOSTIN, Henrique. LIMA, Edson Pinheiro de. COSTA, Sérgio Eduardo Gouvêa da. Avaliação das Práticas de Sustentabilidade nas Operações de Serviço em uma Instituição de Ensino Superior. In: Gestão e Desenvolvimento em Revista V. 3, N. 2, jul-dez/2017, p. 127-142. ISSN online: 24468738 Artigo recebido em: 23/06/2017 Artigo aprovado em: 23/11/2017. Disponível em: <file:///C:/Users/micae/Downloads/17134-69866-1-PB.pdf. Acesso em 18 Jun. 2018.

GADOTTI, Moacir. Qualidade na Educação: Uma Nova Abordagem. In: Congresso de Educação Básica - COEB, 2013. Disponível em: 
Micaele Rodrigues Feitosa Melo;

Ângela Maria de Souza;

Agna Ligia Pinheiro Máximo;

Antonio Thércio Silva Coutinho

http://www.pmf.sc.gov.br/arquivos/arquivos/pdf/14 $022013 \quad 16.22 .16 .85 d 36816927$ 86726aa2c7daa4389040f.pdf. Acesso em 15 Ago. 2017.

JACOBI, Pedro. Educação Ambiental, Cidadania E Sustentabilidade. Faculdade de Educação e do Programa de Pós-Graduação em Ciência Ambiental da USP. In: Cadernos de Pesquisa, n. 118, março/ 2003 193. Disponível em http://www.scielo.br/pdf/\%0D/cp/n118/16834.pdf. Acesso em 02 Ago. 2017.

LIMA, Gustavo da Costa. O Discurso da Sustentabilidade e Suas Implicações para a Educação. In: Ambiente \& Sociedade - Vol. VI n. 2 jul./dez. 2003. Disponível em: http://www.mma.gov.br/port/sdi/ea/deds/arqs/gustlima ambsoc.pdf> Acesso em 15 Ago. 2017.

MARCOMIN, Fátima Elizabeti; SILVA, Alberto Dias Vieira da. A Sustentabilidade no Ensino Superior Brasileiro: alguns elementos a partir da prática de educação ambiental na Universidade. REV. CONTRAPONTOS - Volume 9 n 2 pp. 104 - 117 - Itajaí, mai/ago 2009. Disponível em:

https://www6.univali.br/seer/index.php/rc/article/view/999/1104. Acesso em 02 Ago. 2017.

MIGUEIS, Claudia Maria Vieira. Educar para a Sustentabilidade: príncipios e práticas sustentáveis em escola estadual rural da região metropolitana do Rio de Janeiro In: X CONGRESSO NACIONAL DE EXCELÊNCIA EM GESTÃO.

Disponível em: http://www.inovarse.org/sites/default/files/T14 0171 5.pdf. Acesso em 05 Out. 2017.

MIRANDA, Maria Geralda de. PEREIRA, Alexandre de Jesus. Questões

Ambientais: Sustentabilidade e Currículo Abordagens Práticas e Teóricas. In:

RPI - Revista de Pesquisa Interdisciplinar, Cajazeiras, v. 1, n. 1, 47-57, jan/jul. de

2017.Disponível em < file:///C:/Users/micae/Downloads/128-500-1-PB.pdf>. Acesso

em 18 Jun. 2018.

RAMOS, Margarete da Silva; RAMOS, Ronaldo da Silva. Educação Ambiental e a Construção da Sustentabilidade Pequenas escolas na construção da ecoresponsabilidade local Revista Visões 4ํㅡㄹ Edição, №4, Volume 1 - Jan/Jun 2008. Disponível em:

http://www.fsma.edu.br/visoes/ed04/4ed Educacao Margarete Ronaldo.pdf Acesso em 02 Set. 2017.

RONCAGLIO, Sônia Maria. A Relação Professor-Aluno na Educação Superior: A Influência da Gestão Educacional. In: Revista Psicologia Ciência e Profissão, 2004, 24 (2), 100-111. Disponível em http://www.scielo.br/pdf/pcp/v24n2/v24n2a11.pdf. Acesso em 18 Jun. 2018.

SHRIVASTAVA, Paul. (2010). Pedagogy of Passion for Sustainability. Journal Academy of Management Learning \&Education. Vol.9, No. 3, 443-455. 
TEIXEIRA, Cristina. TORALES, Marília Andrade . A questão ambiental e a formação de professores para a educação básica: um olhar sobre as licenciaturas. In: Educar em Revista, Curitiba, Brasil, Edição Especial n. 3/2014, p. 127-144. Editora UFPR. DOI: 10.1590/0104-4060.38111. Disponível em http://www.scielo.br/pdf/er/nspe3/a09nspe3.pdf. Acesso em 18 Jun. 2018. 